\title{
AVALIAÇÃO DE CURSOS NA FORMAÇÃO DE PROFESSORES E INDIVIDUAÇÃO DO PROFESSOR DA ESCOLA BÁSICA
}

\author{
Claudia Madruga Cunha \\ Universidade Federal do Paraná
}

\section{Resumo}

Analisa-se neste artigo as possibilidades ou potencialidades de qualificação docente em um processo Institucional intitulado PDE, Programa de Desenvolvimento Educacional, que se realiza como projeto de extensão na Universidade Federal de Paraná, em parceria com a Secretaria Estadual de Educação. Analisando dados colhidos numa avaliação de cursos, tensiona-se como esta formação transforma a vida do professor como indivíduo, pertencente a uma classe e a um meio: a escola básica. Interpreta-se que quando este professor avalia os cursos que recebe neste Programa, traduz aspectos de sua escola não estando nela. Por trás de sua avaliação se condiciona um olhar vindo da escola, que participa daquilo que ele é, como pessoa e indivíduo professor. No risco de se perder de si, estando fora de seu meio, este profissional resgata sua experiência para fundamentar sua avaliação, e, através dela, estes professores tentam se diferenciar, se individuar. A teorização lança mão da perspectiva deleuziana sobre a diferença, dialogando com outros autores, na tentativa de explicitar que nesta qualificação docente, uma prática instituída na escola clama por novos sentidos.

Palavras-chave: Avaliação; Prática docente; Individuação. 


\title{
COURSES EVALUATION AT TEACHERS FORMATION AND INDIVIDUALIZATION OF BASIC SCHOOL TEACHER
}

\begin{abstract}
This essay broach about a teachers' qualification process that is linked to an Institutional Program, which happens at the Paraná Federal University in a partnership with the State Education Secretariat. Analyzing data from courses evaluation, it is render problematic how this formation changes teacher's life like an individual belonging to a class and an environment: the basic school. It is interpreted that when this teacher evaluate the courses received by him in this Program, he translated aspects from his school not being there. Behind his evaluation it is conditioned a view came from school, which participates of what he is by person and by individual teacher. Risking loosing himself being out of his middle, this professional rescues his experience to fundament his evaluation and through it this teacher try to differentiate himself, to individualize himself. The theorization utilizes the Deleuze's perspective of the difference, dialoging with others authors, in the effort to make explicit at this teachers' qualification, a practice institutionalized at school that clamor for new meanings.
\end{abstract}

Keywords: Evaluation; Teachers' practice; Individuation. 
Algumas das reflexões propostas neste texto se originam e se organizam em torno do Programa de extensão e formação de professores, intitulado PDE ou Programa de Desenvolvimento Educacional do Estado do Paraná, que tem aproximado a Universidade Federal do Paraná das escolas públicas e das instituições de ensino fundamental do Estado. Suas atividades começam no ano 2007, estabelecendo uma parceria entre Universidade Federal do Paraná e as outras instituições do ensino superior do Estado. É um Programa de desenvolvimento profissional docente que oportuniza as reflexões sobre a formação de professores.

Quer se refletir, através de uma análise dos resultados da avaliação dos cursos e outras formas de registro qualitativo destas ações formativas, as possibilidades ou as potencialidades desta formação, na transformação da vida do professor como individuo, que pertencente a uma classe se relaciona de um modo especial com o seu meio: a escola básica.

Neste sentido, se pondera que quando este professor avalia os cursos que recebe neste Programa de formação continuada, sob os efeitos de um processo de deslocamento, processo que o arrasta de um estado de si a outro. No momento em que ele avalia as práticas e os conteúdos que recebe nos cursos ofertados por esta formação, interpreta a escola não estando nela. Nesta avaliação, algo o condiciona a percepção da própria profissionalização, condiciona-o a um olhar para escola que participa daquilo que ele é, como pessoa e indivíduo professor.

Problematiza-se que, se por um vértice que sustenta esta formação, há um deslocamento geográfico do professor do ensino fundamental e básico, que o afasta por um ano da sua escola ao passar ou a voltar a frequentar o ambiente universitário, por outro, este mesmo deslocamento dá início a uma experiência ou processo de alteração de si, de individuação deste professor, que é fruto subjetivo do seu abandono do seu meio para se hospedar em um outro meio. O professor da escola deslocado de seu ambiente e contexto, é incumbido de analisar sua prática, numa análise em si de si, esforçando-se ou não é movido para se transformar em outro nele mesmo, sob um 
processo conceituado por Simondon (1993) e aceito por Deleuze (2010) de individuação.

Este Programa proporciona um diálogo constante entre Secretaria Estadual de Educação e a Universidade Federal do Paraná que objetiva a formação continuada de professores. Ao se dirigir ao desenvolvimento da educação básica articula a Universidade com a Secretaria de Estado da Ciência, Tecnologia e Ensino Superior (SETI), a Secretaria de Estado da Educação (SEED) e os Núcleos de Curitiba, Região Metropolitana e Litoral. Teve início no de 2007, quando o Governo do Estadual do Paraná, passa a implementar políticas de melhoria da educação básica, inspirado em ações do Governo Federal que se organizavam na mesma direção. Ameaçado de extinção pelas trocas de governo, este Programa garante sua sobrevivência quando deixa de ser uma política de governo e se torna política de Estado, no ano de 2010, pela Lei complementar n. 125/10.De modo geral o objetivo desta formação é melhorar a Escola investindo no professor, na educação continuada dos profissionais da rede estadual. Estes professores são selecionados por critérios pré-definidos, possuem de direito o afastamento de suas atividades, durante o primeiro ano. Com a duração de 960 horas, esta proposta curricular, prevê que os docentes recebam cursos e concomitante a isto, realizem um projeto de intervenção, que vira material didático a ser aplicado na escola; por fim, como conclusão, exige a escrita de um artigo sobre essa experiência.

A formação de professores no Programa é composta por quatro etapas distribuídas em dois anos. No primeiro ano estes professores se afastam integralmente da escola. E neste retorno à Universidade participam de cursos gerais e específicos nas suas diferentes áreas de formação. Estudam, frequentam cursos e refletem seu contexto escolar em contato com um orientador. No primeiro semestre é imposto a todos propor, a partir de um aprofundamento teórico, um "projeto de intervenção"; já no segundo semestre, produzir um material didático para dar suporte à inovação delineada. No segundo ano de curso e terceiro semestre, devem voltar a escola de origem para aplicar o material recentemente escrito. Por fim, no 
quarto e último semestre, é o momento de escrever o "artigo" que descreve e problematiza todo o processo. Há um pressuposto, nesse desenho curricular, que estimula o professor a fazer um diagnóstico da escola e de sua prática docente, para depois agir sobre ela, incluindo os dilemas sociais e profissionais que encontra em seu cotidiano.

A Universidade organiza a oferta de disciplinas e de seminários que comporão o percurso de formação, relativas à formação docente oferecida. Seleciona, nos seus quadros, os docentes que ministrarão as aulas e orientarão os trabalhos monográficos. Essa seleção leva em conta a disponibilidade dos professores em participar do Projeto e seu compromisso e saberes para com o campo da formação docente.

Os materiais produzidos pelos professores cursistas fica disponibilizado no portal chamado www.educacao.pr.gov.br. Trata-se de uma ferramenta que permite a interação com os colegas que estão nas escolas. Os temas mais frequentes destas produções explicitam mudanças culturais da sociedade, são questões que ligadas a diversidade e ao uso da tecnologia, tem indicado alguns vetores daquilo que fragmenta a escola atual. Implicam sintomas de uma organização curricular de certo formato "inter-rompido" por vários aspectos que desafiam a instituição escolar. Esses elementos fragmentários convivem com a linearidade das práticas e dos conteúdos das áreas do nível básico.

As constantes alterações do contexto social têm deslocado a escola e o currículo para nova forma, em alterações que implicam o professor e sua prática. Sob o prisma destas mudanças, ambos espiram uma formação inicial que se realizou em outros tempos desenhada em outro contexto na universidade. O tensionamento destes temas levam a escola a uma précondição tal que ela enquanto meio formador passa a ser provocadora de novas concepções teóricas e práticas.

As considerações aqui propostas se tecem no contato direto com esta formação de professores, sendo colaboradora do programa desde 2008. Trabalhar a metodologia da pesquisa em educação com estes professores amplia as reflexões sobre o aprendizado docente; assim como, tem revelado 
ao meio acadêmico limites e desafios no enfrentamento das questões do meio escolar, ambiente que os temas dos projetos de intervenção passam a ressignificar, atualizando no nível do ensino superior a imagem de um coletivo que trabalha a base. Das incertezas e inseguranças a respeito das possibilidades e potencialidades de suas práticas, se destaca uma imagem de professor, um perfil profissional que este docente carrega consigo, quando descreve a si e a seu meio nos desenhos que se tornarão intervenção.

Trata-se de um profissional que vindo de um meio predisposto a uma rede frágil de relações sociais e conflitos de classe social, raça, gênero, faixa etária, e outros, sofre as restrições impostas por seu contexto, sofre tensões que não cansam de o desafiar. Terá que utilizar procedimentos e criar alternativas que possibilitem contribuir para uma alteração de sua prática profissional na escola. A ideia forçosa de ter que criar condições novas, que estabeleçam uma melhora qualitativa daquilo que já faz ou quer fazer nas práticas de ensino da sala de aula e no contexto escolar, faz com que ele subjetivamente queira se individuar, se diferenciar, uma vez que pertence a um grupo no qual interfere e é interferido.

Antecipa-se que este professor quer crivar, destacar algo seu, algo que diz do modo como ele resiste ao próprio meio a que pertença, na academia se percebe em outro, sem sua rotina estressante e incessante de demandas, se sente deslocado, solto, desvalorizado, desentendido. Por fim sem recorrer a psicologismos, interessa compreender como este profissional resiste a dar a si novos contornos que o correlacionem de uma maneira nova a aquilo que já é parte de seu fazer. Procura-se explicitar - através de uma análise de dados colhidos do resultado de uma avaliação, aplicada ao final dos cursos , que certa individuação vinda destes professores ou da sua capacidade de diferenciar-se, aqui analogizada como uma metaestabilidade que o condiciona a uma vida de professor, pode ser percebido, nesta formação continuada, como algo dá vazão ao teatro da individuação, a algo que vindo da rotina dele/s e nele/s, traduz sua diferenciação profissional. 
Não se trata de dizer que o professor da escola básica se avalia quando avalia os cursos que recebe, mas do que é possível resgatar da experiência do professor, aquela que ele já carrega em si e possui significativo potencial de análise. Passível de ser compreendida e explorada por diferentes olhares teóricos e metodológicos. Logra-se perceber como se realiza esse processo de formação que se dá sobre uma formação já existente, o que pressupõe uma necessidade intrínseca da avaliação da prática docente, levando em conta ações de ensino-aprendizagem medianamente consolidadas. Em outras palavras se reflete sobre como o professor, no contato com outra prática docente, movimenta seu estado de ser professor.

Para analisar como este profissional se modifica sendo o mesmo, convocase a perspectiva deleuziana sobre a diferença. Sobre esta perspectiva teórica se dialogacom outros autores, na busca de analisar como esta formação que, entre outras, se realiza no interior da Universidade Federal do Paraná, tem contribuído para qualificar/avaliar uma prática docente que se institui na e para a escola, na intenção de uma re-formação da docência.

Propõe-se que o professor da escola básica, no deslocamento de um meio a outro carrega algo individuado diferente, subjetivado diferente, que se expressa naquilo que faz dele um membro de uma classe, o diferencia, vindo de seu grupo e meio. Um perfil profissional é extraído do seu meio, subjetivado diferente, demandando algo relacional-cultural da escola básica. Uma perspectiva nele favorece uma representação sob a qual avalia os cursos que recebe nesta formação. Ao problematizar seu contexto e prática, este professor cursista, exercita o pensar a própria prática, sofre alteração de sua singularidade, num processo que denominou Simondon (1993) individuação.

Logo, possíveis mudanças nas práticas dos professores das escolas básicas do Estado do Paraná são possíveis como produto ou efeito das intercessões que se fazem entre uma perspectiva docente que vem da escola e seu encontro com uma formação que se faz no ambiente acadêmico. O professor do ensino básico altera sua ação, quando se desloca do meio que precede e 
faz contato com outra prática docente que o envolvem com o estudo e a pesquisa.

As atividades de formação realizadas no interior da Universidade movimentam esse meio, o provocam, no diálogo desta formação docente com a produção de conhecimento que agrega saber a áreas especificas e com as práticas que condicionam um perfil aos Cursos de Licenciaturas. Como disse Moreira (2006) "a permanência de preconceitos, cujas raízes se encontram fora da escola, continua desafiando os esforços dos que preparam os futuros professores e carece de investigações que apontem melhores formas de enfrentá-las".

Neste sentido, os problemas que os profissionais da educação básica laboram no meio acadêmico, instigam a formação inicial a uma escuta da escola. Em geral os cursistas deste programa revelam características interessantes da experiência profissional na instituição básica, muito embora, nem sempre se possa dizer, que todas estas características os qualifiquem do ponto de vista profissional. O ingresso ou retorno aos centros formadores, para muitos destes profissionais da educação básica, significa não apenas a retomada da experiência à luz das fontes teóricas, mas a oportunidade de adquirir conhecimentos para melhor adequarem-se a função que estão ou passaram a desempenhar nos ajustes dos quadros efetivos.

\section{Efeitos e intercessões entre escola e universidade}

Esta formação ao mesmo tempo em que mostra ao meio acadêmico interessantes experiências e outras, que se realizam nas instituições de ensino básico do Estado, apresenta junto a este hóspede temporário, diversas fragilidades. Muitos destes profissionais percebem que sua formação inicial se desatualizou na passagem do tempo, os conteúdos que trabalham são mecanicamente renovados através dos livros didáticos, a rotina da escola não os habilita nem incentiva a renovação das práticas. O processo de ensino que organizam se defasa, falta uma potência que neles renove a busca por conteúdos e conceitos, mostra-se deficiente a condição de 
individualmente procurarem renovar as práticas e as experiências, comumente repetidas na rotina da escola.

Dá para se dizer que os problemas mais comuns nos projetos destes professores, apontam temas que ficam expostos, em muitos casos, as ausências de saberes que desarmam ou despreparam estes profissionais para operar com o que se diversificou no contexto da escola da atualidade. Revelam um conjunto de questões socioculturais e outras vindas dos avanços da tecnologia, que igualmente impactam aquilo que enfrentam na ambiência da sala de aula. Desafia-os trabalhar com uma escola ambígua, indisciplinada, despolitizada, descrente, indecente, que se fragmenta sobre outra escola, unívoca, tradicional, conservadora, ideológica, cristã, reguladora.

Uma escola e uma não escola, uma tradição e uma reformulação de um contexto societário convivendo num mesmo ambiente, onde este professor se analisa. Ofertar cursos para este professores é se expor às reflexões e reclames deles. Narrativas advindas de um prisma onde a estrutura e ordem organizacional institucional revelam suas tendências e

pressões, pois facilmente se mostram abalados em seus estados emocionais. É visível a disposição de um grande número destes professores de perder o controle do que fazem, estando em ambiente alheio ao seu. As certezas que sustentavam certa finalidade na relação estudo e ensino, ficam soltas, estando na condição de alunos o processo educativo torna-se não atrativo.

Neste sentido, atualizar sua formação pode ser entendido como demanda sem precedentes, posto que, vinda do Estado e da sociedade esta urgência mostra que o professor não está apto para trabalhar com os problemas que nos seus projetos se formula. Indica que a formação continuada já se dá sob um diagnóstico negativo, que recai sobre um olhar do professor sobre si e sobre seus pares. É bem comum se observar que os professores creem, muitas vezes, que para reformar ou melhorar a escola é preciso mudar o outro professor, colega seu que não é um bom professor. Nos projetos de intervenção uma escrita de estilo restritivo e justiceiro, explicita claramente que estes professores interpretam determinações que julgam válidas e 
acabam por revalidar discursos reguladores, no desejo demudar seus colegas e suas práticas,assim como, as consequências destas para os alunos.

Este cenário de reformas onde os professores da escola, pedagogos e gestores querem reformar em primeiro lugar seu colega, outro de si que também é professor, aponta as vulnerabilidades de um sistema, meio e espaço institucional, de finalidade educativa.

Duas perspectivas e alguns efeitos se podem apontar disto: uma considera que a formação que se realiza no interior da universidade está apta para potencialmente atualizar uma prática docente que se abriga na escola; outra que mostra que o professor da rede básica, ao se dispor a problematizar seu contexto, de algum modo é atingido por este processo. Resulta que a avaliação que eles fazem dos cursos que recebem, convive com estas duas perspectivas, produzindo efeitos ou intercessões entre a prática docente que vem da escola e a formação profissional do professor desenhada no meio acadêmico.

Com todo este contexto se quer dizer que o professor recebe esta qualificação de um modo vertical e avalia o que lhe ofertam desde um lugar não muito confortável, pois se insere em um outro contexto que abre o seu meio a discussão, declarando de antemão fragilidades naquilo que ele faz. Logo o poder avaliar os cursos que recebe nesta formação, o estimula e o tenciona, move nele um resgate de si, daquilo que ele traz diferente de meio; tal diferenciação, provoca sua individuação e o abastece para o resgate daquilo que é seu, em outro meio. O meio se mostra o antídoto que o professor cursista PDE utiliza, pois como disse Janela Afonso (2005, p. 19), “a avaliação é ela própria uma atividade política", seus efeitos não se separam desta ordem.

Este relato analisa o resultado da avaliação da turma PDE 2012-2013, trabalha os dados colhidos no ano passado, 2013, ao final dos cursos organizados e ministrados na Universidade Federal do Paraná. A turma 2012- 2013, aqui analisada, possuía165 alunos, todos frequentes nos cursos ofertados, dos quais apenas $15 \%$ não respondeu o documento de avaliação. 


\section{Avaliação na análise do meio escolar}

Interessa observar que o professor PDE vem avaliando os cursos que frequenta de dois modos: um deles quando responde as questões que lhe chegam ao final de cada curso e, outro de forma espontânea, quando recorrem à coordenação deste programa para registrar suas impressões sobre as aulas frequentadas. $\mathrm{O}$ que se observou na leitura destes registros é que, em ambos os modos, se traduzem impressões vindas destes profissionais ligadas a seu meio e suas práticas. Os constantes desafios de suas experiências, lhes propicia uma análise que vem de seu meio, constantemente recortado, fragmentário, movido por tensões que esgotam e ultrapassam os conteúdos que dispõem e devem ser traduzidos no enfrentamento da realidade da escola pública. Exigidos a problematizar a realidade escolar, demandam que nos cursos já se aventem soluções para suas questões mais comuns: violência, indisciplina, desinteresse, segregação de classe, raça e gênero.

São 256 horas de cursos em um ano, ministrados pelos professores da universidade, 128 horas no primeiro semestre, 64 horas de "Metodologia da Pesquisa em Educação" e outras 64 horas de "Fundamentos da Educação"; no segundo semestre, recebem outras 128 horas de cursos cujos conteúdos se referem a área do ensino básico que o cursista se inscreve no programa ou ao padrão a que pertence na escola. Além desta carga horária, ainda, precisam frequentar 64 horas de seminários, simpósios e/ou cursos de extensão oferecidos nas Instituições de Ensino Superior ao seu alcance. Em meio aos cursos e outros, devem comprovar frequência em oito encontros de orientação a cada semestre. Também recebem dos Núcleos Regionais que estão ligados, 48 horas de cursos que os atualizam nas tecnologias para que possam utilizar a plataforma virtual "Sacir" e nela, postar seus documentos e interagir com outros colegas profissionais da rede pública estadual do Paraná.

É um programa de formação complexo, centraliza no professor não apenas as mazelas do processo educativo, mas, também, suas possíveis soluções. 
Sem se desfazer desta carga, o professor avalia os cursos que recebe por um duplo critério, que implica nele o seu meio como problema e o encarga de uma solução, que para além do meio é solução de si. Revolvido em sua individuação o professor da escola básica mostra, nas suas avaliações, a presença de inúmeros preconceitos. Alguns deles vindos de contextos culturais mais conservadores, reclamam das perspectivas emancipatórias dos discursos de raça, gênero, etnia presentes nos ministrantes de curso e outras das posições políticas que se explicitam e envolvem elementos culturais e religiosos. Como disse Luckesi "a avaliação como ato diagnóstico tem por objetivo a inclusão e não a exclusão; a inclusão e não a seleção - que obrigatoriamente conduz a exclusão" (2000, p.172). Portanto, quando se analisa os comentários propostos nos instrumentos avaliadores dos cursos gerias e específicos, deve se levar em conta as situações que direcionam aquele que avalia, as condições que o precedem no ato de avaliar.

Dos reclames registrados no decorrer dos cursos, poucos pediram intervenção direta, após as aulas dadas. Mesmo vindos de manifestações espontâneas são registrados e compõem uma escuta importante sobre o perfil dos professores da rede estadual. Uma escuta sobre o que os afeta incomoda, os desestabiliza. Suas avaliações descritivas produzem um diagnóstico que diz de suas perspectivas, revelam compromissos e visões de mundo. Neste sentido, colocar em discussão os cursos que se oferece, dá a universidade a possibilidade de utilizar a avaliação, como disse Dias

Sobrinho (2003, p.93), como ação “fundamentalmente política por que pertence ao interesse social e produz efeitos públicos de grande importância para as sociedades".

A proposta de avaliar o que se oferta aos professores da rede básica como conteúdos e práticas nestes cursos, dá oportunidade de diálogo entre um meio e outro - escola e universidade. Para Dias Sobrinho (2003), há na avaliação uma tendência geral de explicitação dos conflitos de cultura, paradigmas e outros elementos que se associam ao conhecimento e ciência na sociedade contemporânea. O modo como se apropria das áreas e do 
conhecimento que as alimenta, é muito diferente em um meio e outro. Tal diferença precisa ser explicitada ao se problematizar a prática docente, pois aponta para realidade que pode vir a revelar efeitos e intercessões, transformações, entre indivíduo professor da escola pública e esse novo meio que temporariamente o hospeda, - a universidade.

Avaliando um outro que também é professor, o professor que vem da escola avalia sua própria condição. Faz da sua experiência, do exercício de traduzir o conteúdo e com ele expor-se a realidade da escola, aquilo que o torna um outro professor, que o diferencia do especialista acadêmico. Esta exposição a um meio no qual se percebe muito mais instável está implícita nas suas observações.

O instrumento de avaliação que recebe, abrange informações sobre o local do curso; carga horária prevista; metodologia utilizada; material didático; conteúdos; contribuição para o seu projeto de intervenção e contribuição para o seu desempenho profissional. No último ano dos 165 professores cursistas $85 \%$ responderam a este instrumento. Embora se mostre ainda restrito na sua abrangência, este instrumento de avaliação produz algumas respostas interessantes uma vez que como defende Dias Sobrinho (2003, p.95), "objetiva a melhora das funções propriamente educativas" desta formação e permite diagnosticar alguns problemas durante os cursos e sobre a continuidade dos mesmos.

Quando o professor da escola básica avalia por instrumentos os cursos que frequenta,

Principalmente, os chamados Cursos Gerais (Fundamentos da Educação e Metodologia da Pesquisa em Educação), localizados no início da formação, mostra uma tendência positiva nas suas observações. Já no segundo semestre ele tende a ser mais crítico quando avalia os Cursos Específicos de sua área. Nesta turma 2012-2013 se ofertou 128 horas de curso para cada uma das seguintes áreas: Educação Física, Educação Especial, Ciências, Filosofia, Física, Geografia, Gestão Escolar, História, Língua Estrangeira Moderna, Língua Portuguesa, Matemática, Pedagogia, Química, Sociologia. Pode-se observar, neste período, a queda do número de respondentes. 
Sobre estes cursos a avaliação também tende a ser positiva, na sua maioria. Embora aumentem as manifestações de insatisfação, no que refere a relação entre conteúdo e material didático de intervenção. Isto ocorre por que é o momento onde aumenta a ansiedade de todos com o preparo do documento educativo, com o qual vão intervir no meio escolar.

Nesse conjunto de cursos avaliados duas áreas tenderam $100 \%$ a uma avaliação positiva, são cursos oferecidos em parceria com a Universidade Tecnológica do Paraná, que tiveram pouco menos de 20 cursistas: Matemática e Educação Física. Com pouco mais do dobro de frequentes e 48 respondentes, os Cursos de Geografia e de História, talvez por serem áreas de conteúdo mais crítico, deram um ótimo retorno à avaliação, colocaram suas expectativas, propuseram alterações e outras análises sempre em torno dos conteúdos. Já o grupo da Pedagogia e da Gestão Escolar, tendo em torno de 30 cursistas, apresentou o maior índice de insatisfação, em torno de $10 \%$ destes, criticaram o espaço físico e o conteúdo dos cursos. As outras áreas não citadas deram respostas, no geral, positivas a avaliação, sem utilizaram dos campos descritivos. No total geral a avaliação dos cursos foi positiva, as 19 descrições, críticas e reclames se dirigem.

A partir da análise do grupo da área de História e Geografia - cursistas que mais utilizaram o campo descritivo são trazidos alguns dos comentários agrupados pela sua proximidade argumentativa, sendo que o número entre parênteses se refere ao número de respondentes (5) “o conteúdo é interessante, mas não adianta em nada para o projeto que quero fazer"; (3) "tinha que mudar a didática, as aulas são muito longas e cansativas"; (2) "a professora é muito inteligente, mas é filosófica demais, não é prática"; (2)“"este curso não vai me servir para nada"; (1)“o professor foi muito complexo, não trouxe a aplicação"; (1)"queria ver esta professora trabalhando este assunto numa turma do sexto ano"; (1)“não se pode questionar o professor! Não há liberdade de expressão na universidade?"; (1) "o professor sabe muito, é muito inteligente, mas não entende de escola"; (1) "o professor diz muito palavrão, não fala a linguagem da 
escola!”; (1) “o conteúdo é tudo muito bonito, interessante, mas não lá pra escola".

Já do grupo da Pedagogia e da Gestão Escolar, em torno de 55\% deram respostas objetivas e consideraram ruins os seguintes itens: local do curso; carga horária prevista; metodologia utilizada; material didático; conteúdos; contribuição para o seu projeto de intervenção e contribuição para o seu desempenho profissional. O campo descritivo foi pouco utilizado, foram respondentes que fizeram comentários rápidos que repetem o que o grupo anterior já expôs.

Estas avaliações provocam um olhar não apressado para a interpretação dos dados. Parece prematuro impor conclusões, a partir de uma turma analisada, se vê como necessário uma investigação mais larga que avance novas edições destes Cursos para que se possa trazer certos resultados. Contudo, se pode antecipar estando envolvida com esta formação, que o meio universitário tende a teorizar o espaço escolar, sobre os aspectos de suas contradições e tensões num âmbito mais amplo; enquanto que, a expectativa dos professores cursistas vinculada a seu meio e situação de formação, centra-se na relação problema e solução do que acontece na experiência direta de sua sala de aula.

Este retorno do "professor da escola básica" à universidade, traz dele uma condição de docência pré-formal do ponto de vista do conteúdo e uma condição já formada do ponto da experiência. O vínculo dele com os conteúdos propostos na universidade pode reestabelecer sua relação com os especialistas de sua área, adquirir recentes conceitualizações para novas abordagens. Entretanto, a consagração da prática e a necessidade de construir com ela vínculos múltiplos com o cotidiano, faz com que este profissional receba atualização de conteúdos como uma ferramenta que pode dispensar.

Há uma tendência deste profissional se apegar aos elementos novos e passageiros, instrumentos, técnicas e outros instrumentos da cultura popular, que assim como surgem se vão, para incrementar sua prática. Parecem esquecer-se de alimentar sua condição de pensamento, condição própria a 
sua especificidade profissional, aquilo que poderia diferencia-lo qualitativamente em seu meio profissional. Este desprezo ao conteúdo ele paga com indefinição de sua individuação, de seu diferenciar-se. Adapta-se o professor às novas tendências e quer adaptar seu meio em outro meio. Fragmentado pelos cenários sobrepostos, estes professores refletem a própria prática na prática de outro professor, embora temam incorporar algo que revise sua ação profissional, de um modo mais denso.

\section{Avaliação e efeitos na formação de professores}

Disse Dias Sobrinho (2003) que toda avaliação produz efeitos. Esta ação avaliativa retroage sobre o professor da escola básica quando ele avalia os professores da academia. Pode-se perceber, resgatando Deleuze (2010) e Simondon (1993), que há algo no professor da escola básica que o individua, o revitaliza por um outro olhar de si, quando objetiva num processo educativo a prática e a experiência que carrega e que fazem dele um ele mesmo, um ou alguém em meio ao seu meio, ideologias, valores, jogos de interesse e disputas de poder.O processo de individuação vem do contato com o meio a que este prisional pertence, do que lhe é externo; vem do modo como este profissional faz relação com outro ambiente, meio outro no qual ele é inserido se percebe a si e a seu entorno, num propicio alargamento de sua consciência de si.

Quando utiliza o instrumento de avaliação interpreta-se que o professor expõe sua relação com outro, com o professor acadêmico, capta tendências, projeções, perspectivas de um modo ideal de ser professor. Capta energias dispersas, complexas influências de outro meio sobre aquele que carrega em si. Nisso, redefine sua consciência e na medida em que exercita um potencial que o dispõe a isto, usa a própria experiência para avaliar seu outro. Tal avaliação em movimento, o modifica em um processo singular, subjetivo e individual que encontra guarida na teoria da individuação tomada por empréstimo de Deleuze (2010), do que ele interpreta e aceita da individuação em Simondon (1993). 
Neste processo de formação mesmo que de modo imperceptível o professor da escola básica se transforma, passa de um estado a outro. Muda ou se altera por que se desloca de seu meio; por que recebe cursos, estuda, escreve; por que avalia um outro que como ele e em meio diferente dele, é professor. Utilizando o conceito de diferença de Deleuze (1998) se diz que o que é diferente entre um outro não está diretamente ligado à questão do primado da identidade ou da representação; a diferença se vista de um modo mais amplo, se opõe a simples noção de negação da identidade. Com esta perspectiva se sustenta que o professor que passa por uma formação não se transforma em outro dele mesmo, mas em outro nele mesmo. Ele não se transforma por que colhe coisas, conteúdos e práticas, de um outro professor para si, mas por que projeta a si, seu contexto e sua prática, em um outro professor.

Tal deslocamento de perspectiva de um profissional a outro, permite pensar esta formação por outro aspecto. O processo que o currículo desta formação estabelece propõe a construção de um perfil de professor que utilize, no meio escolar, a pesquisa como base de ensino. Como a pesquisa é sempre vinculada ao meio acadêmico, muitos dos colaboradores deste programa não incentivam seu deslocamento para outro meio. Dizem que a pesquisa necessita de aparatos teórico-metodológicos especializados, que esta atividade não é algo universal para os professores. Os profissionais na academia também possuem dificuldade de entender a especificidade do projeto de intervenção, que no caso desta formação, desenha um material didático-pedagógico que será utilizado e aplicado na escola de origem dos professores. Ambos materiais problematizam a escola, aprofundam, renovam ou agregam novos conteúdos, os que dado a sua relevância podem melhorar as situações do aprendizado na sala de aula ou na gestão do processo educativo, da escola como um todo.

Esta organização de um processo de pesquisa cuja tendência é virar uma prática, pode deslocar a pesquisa, e esta já será uma outra pesquisa, que saindo do meio acadêmico passa a frequentara escola, no retorno destes professores. Entretanto quando o professor retorna ao mesmo cenário e aos 
mesmos hábitos, tende a fortalecer o que no seu meio de origem fragmenta as condições de transformação ou renovação. O meio o força a um retorno, sem perceber o processo de mudança do mesmo no mesmo, no percurso deste professor. Gilbert Simondon (1993) traz a questão da individuação que Deleuze (2010) explora quando critica as teorias atomistas, hilomórficas e substancialistas ${ }^{1}$ que dizem que a individuação tem sido proposta como algo que corresponde a um sujeito ou individuo já constituído. Ambos os autores nos mostram uma tendência da individuação se dar sobre um ser já individuado $^{2}$, antes mesmo do processo se explicitar no momento atual, como operação.

\section{Diferença do diferente - na pesquisa da prática}

Utilizando esta perspectiva se diz que o professor da escola básica retorna à universidade já possuindo uma formação, passível de se fazer uma analogia com a individuação. Nas bases do pensamento ocidental, Platão disse que cada coisa que é ou existe possui uma forma que por sua vez corresponde a uma ideia. Com Platão se pode dizer que, independente do meio formador em que ele está e do plano político-social da instituição que ocupa, existe uma forma e um conceito que lhe compõem um perfil do professor. Este perfil antecipa, fundado na tradição, uma medida sob a qual o professor avalia outros professores e é avaliado por este coletivo. Diferentes perfis ocupando espaços de ação educativa em planos formativos diferentes, não deixam de cristalizar ideais e modelos ser para o professor.

Potencializando a diferença, Deleuze (2010) critica a tradição platônica, que diz que em um tudo que existe há um modelo ideal que o pressupõe.

\footnotetext{
${ }^{1}$ Simondon (1993) se recusa aceitar a concepção monista e substancialista do ser e o dualismo hilemórfico do indivíduo. O monismo substancialista pressupõe que o ser corresponde a uma unidade atômica, constituída de um núcleo de permanência estável, que resiste e subsiste por si só. Segundo o dualismo hilemórfico, o indivíduo é o resultado ou o composto engendrado pelo par matéria e forma.

${ }^{2}$ Simondon entende que tanto o monismo substancialista quanto o dualismo hilemórfico parecem pressupor a existência de um princípio de individuação que antecede ao próprio processo de individuação;percebe que as duas correntes tendem explicar o individuo já dado e constituído. Para o atomismo o individuo resulta de um precário corpo físico; para o hilemorfismo, resulta de uma conjugação matéria e forma. Segunda Simondon as duas correntes se equivocam ao entender que a individuação como principio, possa vir antes do processo mesmo de individuar-se; este processo vai do pré-individual ao real "individuado" (Cf. Simondon, 1993).
}

Olh@res, Guarulhos, v. 2, n. 1, p. 81-108. Maio, 2014. 
Reclama o filósofo, que sob esta influência, "mete-se a individuação por toda parte" e se faz dela um caráter coextensivo ao ser,pelo menos do ser concreto. Esta noção de individuação influenciou a noção de indivíduo sob qual se funda a escola moderna no século XVII. Posteriormente foi reformada no século XX em sua concepção e no objetivo de educativo passou a ser substituída pela noção de cidadão.

A individuação é parte de um processo de diferenciação do mesmo no mesmo, não conduz a incorporação de modelos, mas sim transformação como decorrência de estado de si a outro. Nesse pressuposto, ao descrever e problematizar sua prática, o professor da escola básica se descreve. Movimenta o outro de si nas suas narrativas, resgata e expressa algo de diferente ou diverso, produzindo uma espécie de singularidade que encontra a tendência de ser analogizada como metaestabilidade tende a uma vida de professor. Esta vida de professor, no contexto das narrativas, dá vazão ao seu teatro da individuação. Busca-se compreender como o professor da escola básica se diferencia de outras docências possíveis, constituindo algo singular para este seu "ser professor".

O professor não só avalia os cursos que recebe como avalia a si e ao seu meio no processo de problematizar, numa escrita que pretende ser interventora, sua prática e as práticas alheias. $\mathrm{O}$ tom punitivo ligado a avaliação (cf. LUCKESI,2000), que figura no plano de uma educação escolarizada, constantemente aparece numa análise dos termos e dos problemas, apontados com mais ou menos frequência nas narrativas destes profissionais. Explicita-se nestas escritas os aspectos que indicam simples generalizações copistas, identitárias e outras que remetem a deslocamentos de si extremamente superficiais, em contraposição a outros movimentos, que, neste processo coletivo, perfazem ou remetem a individuação destes professores, a capacidade de diferenciar-se.

O professor pesquisa sobre sua prática, compara-se, analisa-se, avalia-se deslocado de seu meio em outro ambiente educativo, convive com seus pares, reforça tendências e não se preocupa em re-dizer o que um outro colega seu já disse. Reelabora os mesmos problemas que outros colegas já 
elaboraram, se refere contextos escolares muitos próximos, faz da pesquisa sobre a própria prática uma tentativa de diferenciar-se. Próximos em suas investigações vão criando um novo ciclo reprodutivo, que fora da escola remete ao que se faz nela, o tempo todo.

Muitas vezes os colaboradores que orientam estes projetos de intervenção, no afã de propiciar ao colega da escola o aprendizado da pesquisa, acabam frustrados. Enquanto que o orientador se preocupa que seu orientando vença conteúdos, este último em geral quer vencer os prazos estipulados pela secretaria estadual. São profissionais que ocupam planos diferentes, vivem tempos diferentes, atuando em processos educativos de diferentes tensões. Contudo, o diálogo entre um meio e outro desloca um olhar profissional sobre o próprio contexto. Como é o professor da escola que está deslocado de sua rotina é nele que repousa a expectativa e a tendência da mudança. Mesmo rejeitando o aprofundamento conceitual e o disciplinamento formal da escrita acadêmica, o cursista deste programa, de modo imperceptível, realiza uma alteração em si de si, quando se analisa analisando sua prática; muda algo no modo como compreende seu meio, e, estando em outro meio, o avalia e se deixa avaliar por este que o hospeda.

As avaliações que os professores colaboradores neste programa registram sobre os cursistas e orientandos, produzem num contra efeito uma perspectiva que muda a análise do ensino superior sobre o ensino básico. Deslocado de seu meio, o professor pesquisa a realidade da sua escola, problematiza seu meio, dando curso a uma possível intervenção. Deleuze (1992) para quem "pensar é criar" entende que o pensamento brota das necessidades vividas pela experiência. Tentando dar conta da sua experiência, do seu vivido, da sua prática profissional o professor cursista do PDE se vê exigido ao máximo, quase conduzido a expiação, quando tem que escrever e produzir conhecimento; mas por meio da escrita e de novos projetos ele poderá ou não,romper certa plástica que aglutina composições ou texturas sociais e de grupo; poderá ou não, reinventar o que acontece em seu cotidiano sobre outras ordens de saberes, de conhecimentos, de técnicas; se abrir ou não, a novas oportunidades profissionais. 
Potencialmente uma forma de ser professor do ensino básico está sendo desconstruída e outra está sendo re-informulada e tem começo quando o professor desloca-se da escola e passa a problematizá-la, num outro meio educativo onde age e interage, produz novas reconfigurações e readéqua sua formação inicial.

Nesse movimento de atualização ou reforma do professor do ensino básico do Estado se pode ponderar ainda dois aspectos: um que refere ao investimento de uma política pública que almeja reformar a escola propondo que o obreiro desta reforma seja o professor; outro, consequência do primeiro, que aponta para um movimento de mudança no qual o professor não muda exatamente seu meio, mas a perspectiva que possui de si pertencendo a seu meio. Processo que Simondon (1993) e Deleuze (2010) chamam "individuação", e no qual uma reforma dos professores, não apenas os re-informa, mas possibilita renovação conceitual e outras interações profissionais.

\section{Avaliação de uma pratica em outra prática}

Disse Dias Sobrinho (2008, p.200) que "a educação é uma prática humana, a avaliação da educação é um processo impregnado de valores". O professor da escola avalia o outro profissional que trabalha na educação superior e "cumpre atividades que carregam significados bastante complexos, relacionados com as questões epistêmicas, éticas, políticas, sociais, econômicas, culturais etc" (DIAS SOBRINHO, 2008, p.200). Realiza essa avaliação numa equidistância, uma vez que compreende o contexto notadamente complexo, Ato que, segundo o autor, aponta não para o empobrecimento ou para fragmentação das ações no meio acadêmico, mas mostra "a possibilidade de múltiplas interatuações e relações" (2008, p.200). Tal deslocamento implica em avaliar uma forma de ser professor que é externa, ainda que ele seja parte dela. Esta validação de uma prática, em outra prática possível de ser professor, se opera por alteração do meio ou por mediação (SIMONDON, 1993). Neste sentido, a pesquisa sobre si e de si se objetiva no olhar analítico, no retorno ou no resgate do que pertence ao 
seu local de trabalho. Revisitado a experiência que traz de si, este forçoso produtor de conhecimento sobre a própria prática, encontra os resíduos de outro profissional professor.

Questões desafiam a continuidade e efetiva motivação para qualificar e pertencer como colaborador ou cursista deste programa. Exige-se ter mais clareza sobre o como o PDE vem sendo acolhido nas escolas, saber: como os professores e seus projetos tem realmente impactado o meio escolar a que pertencem? Outra questão é que estando em atividade há 7 anos, interessa analisar a consequência desta formação, tendo em vista o crescente número de professores que já passaram por ela, como ela tem impactado de modo geral a escola básica no Estado do Paraná?

Trata-se aqui de uma mínima parte de todo um contexto. É possível que, retornando ao cotidiano e as práticas remanescentes a ele, este professor não consiga alterar a cultura escolar, que na largura e longevidade de sua dinâmica, absorvam e paralisam sua inovação. Outros desafios se apresentam ao meio acadêmico, a necessidade de se repensar nesse ambiente a qualidade da formação inicial analisando mais de perto, através desta experiência, a escola e o professor.

Embora o professor da escola básica tenha ainda significativa dificuldade de exercitar uma posição mais crítica em relação a sua prática, a ponto de utilizá-la como uma experiência constantemente transformadora de si e do meio, seus retornos nas escritas dos documentos que avaliam os cursos ofertados pelo programa, e, junto a isto, as produções de projetos de intervenção e materiais didáticos, oferecem ao meio acadêmico pistas importantes para constituir uma formação profissional mais adaptada aos anseios da escola atual. Ponderar sobre os rumos desta formação de professores pode implicar em novos diálogos e colaborações mútuas, que evitem ambiguidades na forma com que um meio avalia e recebe o outro.

Neste sentido, a formação de professores que se faz em meio acadêmico, inicial e continuada, fica interpelada pela constante frequência destes professores em seus espaços formativos, se põe em estado de alerta no momento em que a escola passa a ser diagnosticada e problematizada, 
vivida, no meio universitário. Mesmo se compreendendo que toda aprendizagem se faz em processo, é preciso que a Universidade reafirme seu compromisso com a formação dos futuros professores, tendo essa dimensão como um valor. Nesse sentido, o meio acadêmico estaria potencializando uma atitude mais autônoma do professor em relação às decisões pedagógicas.

\section{Como a investigação da experiência avalia a prática?}

\subsection{No hay forma de expresar la experiencia de la investigacion sin expresarse subjetivamente.}

Tal como dizem na frase acima destacada, Contreras e Lara (2010), o professor de escola básica tende a aprender algo novo sobre sua prática, quando a problematiza num projeto de intervenção, mesmo que este aprendizado seja subjetivo. Ao visualizar desde um outro plano suas experiências de ensino, produz algo novo sobre o que faz e num revés disto, ativa a si mesmo de um outro modo, opera com outros fenômenos e é transformado por eles no decorrer de uma experiência formativa em outro meio.

Ao investigar e trazer para análise os resultados das avaliações de curso que vem sendo ofertados na Universidade Federal do Paraná, vislumbra-se que pode estar ocorrendo possíveis transformações ou interações que acontecem ao indivíduo professor da escola pública e ao meio que o hospeda - a universidade. Tais mudanças, entre outros fatores, são favorecidas de ser analisadas quando um professor da escola avalia outro professor da universidade, diferenciando sua prática e defendendo uma forma de entendimento diferenciada do conteúdo, tendo em vista as especificidades do meio educativo a que pertence. Tendo que necessariamente investigar o que faz, o professor da escola reage com uma análise que vindo da sua prática confronta a prática do meio que o hospeda. Isto implica que estes profissionais resgatam sua subjetividade escolar e a reconstroem, fazendo do trabalho sobre a sua experiência algo que se dá entre alguém, o meio e 
mais aquilo que o ambiente propicia. Contribuindo com essa posição Contreras e Lara (2010) vão dizer

"En los acontecimentos, en las experiências en su sentido singular, temporal e vivencial, lo que se vive, lo que cobra o no sentido, lo que afeta a lo que se vive y a manera em que se hace, no es ajeno a las condiciones politicas, materiales y simbólicas del mundo do qual formamos parte; y en concreto, en el mundo educativo, no es ajeno a las formas instituídas de la educacion" (CONTRERAS; LARA, p.46, 2010).

Os autores auxiliam a compreender que a subjetividade, presente naquele que investiga, e seus efeitos são possíveis de serem observados nos discursos que compõem dados avaliativos. Os documentos aqui analisados de um modo mais geral, outros mais específicos, vindos do contexto desta ação, traduzem um fenômeno educativo e o professor que passa por ele. Pode-se entender que aquilo que é subjetivado no inconsciente deste profissional, a partir da obrigatoriedade de fazer um projeto ou um material didático, produz nele ações que resultam em resgate de dados sobre sua prática, advindos de características puramente externas. Tal resgate o alimenta de critérios para o momento de avaliar os cursos que recebe.

Este Programa de formação ora gestando ora avaliando suas atividades vem se instalando na universidade. Revendo seus objetivos parece querer reavivar qualquer energia estagnada nas suas salas de aula das escolas públicas. Quer permitir ao professor da escola básica traçar seu plano, de reforma de si e do meio escolar, o instigar a renovar seus conteúdos e suas práticas sobre outras perspectivas ou planos, alteridades que implicam o meio acadêmico. Este último atua sobre ele como uma sobre-individuação. Como ele já possui uma formação e pertence a uma área da escola básica, as práticas docentes do meio acadêmico interferem nele como uma nova ordem, em uma ordem do que já é ou pré-existe.

Resgatou-se a noção de individuação vinda de Simondon (1993) aceita por Deleuze (2010), na ideia de oportunizar dizer que sob certo aspecto, nesta formação continuada, os professores da escola básica se alteram. Sofrem uma mudança de um estado a outro, revelando certa singularidade enquanto 
parte do processo de transformação ou atualização, move aquilo que este profissional já é em outro estado de ser ou de devir.

Influenciado pela pesquisa do meio acadêmico e dirigindo os aportes da investigação científica para um olhar sobre si, o professor da escola básica se avalia ao avaliar a outrem e se redefine. Tal mudança de um estado préexistente a outro estado, aberto de devir, potencializa a este profissional manter-se aprendendo com sua prática. Este estado potencial vem de uma energia saída de seu meio que, no convívio temporário com outro meio sócio-educativo, produz algo que o individualiza, o atualiza, mantendo-o em um regime metaestável no que refere ao seu estado anterior. Pode-se aprender com Simondon (1993) a ideia de que o professor nesse meio se desloca a outro meio, se dando a individuação. A individuação é algo que acontece a alguém, muito embora aquele que se individua, não o faça nem a produza de maneira instantânea brusca e definitiva.

\section{Considerações finais}

O processo de qualificação do professor da escola básica começa quando ele se mobiliza para um processo de individuação, que se dá pelo afastamento temporário do seu meio; meio que deixa para trás de si como uma dualidade de ser ele, ao mesmo tempo, meio e indivíduo. Ser um meio empobrecido dele enquanto indivíduo e o que ele não é - o indivíduo mesmo -, aquele que não tem mais a dimensão do meio. Nesse processo de deixar-se de si e tornar-se outro em si de si, faz a passagem de um estado a outro, de um estado que o habita quando interage e é intercedido por algo temporário.

Pode-se dizer que revisar sua pauta profissional não o livra de uma forma antiga que o habitava como professor da educação básica, apenas movimenta o que já era nele individualizado, como um estado pré-dado. Diferindo a passagem de um estado a outro de professor, se altera neste individuo um modo ou um estado vivo. Estado este de fazer-se professor naquilo que o contempla como origem absoluta; que o acompanha na individuação perpétua de uma vida própria de docente; vindo conforme um 
modelo fundamental, diz daquilo que o envolve e o revolve, produz "devires" ou outras possibilidades em sua docência.

Por fim, resultando de duros esforços os projetos de intervenção e o material didático elaborados na universidade, a aplicação da intervenção didática na escola, são desafios que também devem ser enfrentando por este professor, e culminam em um artigo final, que descreve todas as etapas desta formação. Nestas produções muitas coisas se reproduzem, outras se produzem diferentemente, vindo de uma vida própria de professor, que em meio a tantas repetições, cópias e representações já publicadas, mostram potências de uma ação de educar que perfazem um estado vivo, que "conserva em si uma atividade permanente" (SIMONDON, 1993, p.104).

Dessas reflexões se infere que o professor do ensino básico deixa sua escola e passa a frequentar, ainda que temporariamente, uma formação de docência continuada na universidade, realiza um processo de alteração de si que o altera de modo mais subjetivo do que objetivo. Essa condição se mostra como um desafio para a proposição de estratégias que tenham significado e que tragam aprendizagens para os atores implicados nos processos formativos.

As reflexões decorrentes da experiência com este Programa almejam contribuir para a sua qualificação e, também, para o campo do desenvolvimento profissional dos professores. A proximidade com a experiência do professor que tem que analisar sua prática e sua escola, o contato com seus critérios e ideais, os dados colhidos que avaliam os cursos e atividades do Programa, num conjunto, vem permitindo que se investigue com maior clareza a formação e a qualificação dos professores da educação básica no interior da universidade.

Por fim, avaliando os cursos está se avaliando os atuais caminhos oferecidos e as alternativas a uma prática da docência que se dá sobre um outro meio,caminhos em muitos dos seus aspectos desconhecidos na academia, nos conduzem a escola básica. As reflexões decorrentes da avaliação destes cursos estimulam o desejo de propor uma formação docente movente e transformadora, capaz de propiciar ao professor que nela ingressa, as 
condições de alterar subjetiva e objetivamente a si e ao seu meio, numa profissionalidade de sentido vivo para todos.

Olh@res, Guarulhos, v. 2, n. 1, p. 81-108. Maio, 2014. 


\section{Referências}

JANELA AFONSO, Almerindo. Avaliação Educacional - regulação e emancipação. 3. ed. São Paulo: Cortez, 2005

CONTRERAS, José; LARA, Nuria Pérez de (Orgs.). Investigar a experiência educativa. Madrid: Morata, 2010.

DELEUZE, Gilles. Diferença e Repetição (tradução Orlandi e Roberto Machado). Rio de Janeiro: Graal, 1998.

DELEUZE, Gilles. Gilbert Simondon, o individuo e sua gênese físico-biológica (tradução de L.B.L. Orlandi). In. Deleuze, Gilles. A Ilha deserta e outros escritos. São Paulo: Iluminuras, 2010 .

DELEUZE, Gilles; Parnet, Claire. L'Abécédaire de Gilles Deleuze. Entrevista com Gilles Deleuze. Editoração Brasil: MEC, "TV Escola”. Paris; Editions Montparnasse. VHS, 2001.

DIAS SOBRINHO, José Dias. Avaliação - Políticas Educacionais e Reformas da Educação Superior. São Paulo: Cortez, 2003.

DIAS SOBRINHO, José. Avaliação educativa: produção de sentidos com valor de formação. In. Revista Avaliação, Campinas; Sorocaba, SP, v. 13, n. 1, p. 193-207, mar. 2008.

LUCKESI, Cipriano. Avaliação da aprendizagem escolar. São Paulo: Cortez,2000.

MOREIRA, Flávio B. A formação de professores e o aluno das classes populares:subsídios para um debate. In. ALVES, Nilda (org.). Formação de professores - pensar e fazer. 9.ed. São Paulo: Cortez, 2006.

SIMONDON, Gilbert. A gênese do individuo. (Tradução Ivana Medeiros). In. Pelbart, Peter Pál; Costa, Rogério da (orgs.). Cadernos de subjetividade. vol.1,n.1. São Paulo: Hucitec 1993.

WOODS, Peter. Investigar a arte de ensinar. Porto, Portugal: Porto, 1999.

VAILLANT, Denise; MARCELO, Carlos. Ensinando a ensinar- as quatro etapas de uma aprendizagem. Curitiba: UTFPR, 2012. 